\title{
A VOYAGE OF DISCOVERY OR A FAST TRACK TO SUCCESS: MEN WOMEN AND THE MBA
}

\author{
RUTH SIMPSON \\ School of Business and Management \\ Brunel University \\ Uxbridge \\ Middlesex \\ Tel: 01895274000 \\ EMAIL: r.simpson@brunel.ac.uk
}

Dr Ruth Simpson is lecturer in Economics at Brunel University. Her research interests

include gender and management development; the career progress of women managers; organizational restructuring and the impact on managerial work. 


\section{A VOYAGE OF DISCOVERY OR A FAST TRACK TO SUCCESS: MEN WOMEN AND THE MBA}

This paper presents and discusses results of a research project on the personal and career benefits of the MBA. These results suggest women value the experience of doing the course and that this gives them greater $>$ intrinsic $=$ benefits of enhanced confidence and self worth. Men gain greater $>$ extrinsic $=$ benefits of enhanced pay and status and place a greater emphasis on the credential value of the MBA. However, the MBA has less of a transforming effect on how they see themselves and their organisations.

Key words: MBA, gender, career benefits, career barriers 


\section{Introduction}

As women have moved into the labour market in increasing numbers, many have chosen to equip themselves with an MBA. Women now account for approximately one quarter of MBAs in the UK, an increase from 16\% in 1987 (AMBA, 1994). Figures from the US show a similar growth (Sinclair and Hintz, 1991). Despite the popularity of the MBA, little is known about the effectiveness of the qualification for women as they attempt to break through the glass ceiling or whether, as the number of women MBAs increases, we are likely to see a significant increase in the proportion of women in senior management positions beyond the year 2000. Based on the findings of a research project on the career progress of male and female MBAs conducted in the UK between 1995 and 1996, this article considers the effectiveness of the MBA and the role of management education in facilitating career progress.

\section{Past Research}

Much of the work on MBAs and career progress comes from the US where results suggests that women do not progress as far or receive the same level of remuneration as men. Cox and Harquil (1991), in a study of 502 MBAs, found that while there was no significant difference between men and women in terms of career satisfaction, women MBAs had significantly fewer management promotions and that being female had a depressing effect on career success. Moreover, salary growth for women was still significantly smaller than for men even after controlling for performance, age, experience, starting salary and career paths. Some studies indicate that women have 
lower starting salaries immediately after graduation. For example, a survey of MBA graduates of business schools found women earning an average of $12 \%$ less than men with similar experience after completing their course (Roman, 1990; Gitlow, 1992). Others suggest little difference in starting salary (Olson and Good, 1990; Wallace, 1989) or in salaries four or five years post MBA (Strober, 1982; Wallace, 1989) but point to a widening pay gap 8-11 years after graduation (Schneer and Reitman, 1990; Olson and Frieze, 1987). Some of this differential in pay may be linked to gender differences in how MBAs evaluate job offers. Research has shown that men have higher salary expectations and higher salary standards than women (Summers, 1988; Subich et al, 1989) and this may mean that men are less likely to accept a salary offer that is below average for a particular occupation.

The above research suggest a smaller return for women from their MBA qualification. Similar findings have emerged in the UK. While an AMBA (Association of MBAs) survey in 1994 found evidence of considerable career progress after the MBA (there was a fourfold increase in those involved in corporate strategy and planning, over half changed function and two thirds reported that their salary and benefits package had improved), preliminary work by Simpson (1996) suggests that the MBA may not help women as much as men in terms of subsequent career advancement. Similarly, a study by Lloyd (1987) indicates the existence of a wide gap between the numbers of women participating in an MBA programme and those actually making a living on the basis of their studies. In other words, having acquired an MBA women tend to end up in occupations which do not reflect their level of qualification or experience. 
Overall, while evidence supports the view that the MBA is associated with more rapid career advancement, and while there is some evidence to suggest that women do not benefit as much as men, the issue of the nature and the distribution of those benefits remains somewhat sketchy. Kretovics (1999) in a study of the learning outcomes of an MBA programme found that the MBA added value in key areas such as information analysis, sense making and initiative but not in interpersonal or communication skills. Similarly, Boyatzis and Renio (1989) found attending an MBA programme added value on a number of abilities related to effective managerial performance though there was a lack of impact on interpersonal and leadership abilities.

Neither study, however, addressed gender differences in career benefits from the MBA - i.e. whether men and women differ in terms of the nature of skills acquired. Work on conceptualisation and career success among managers and professionals indicates that gender is a strong influencing factor (Sturges, 1999; Russo, Kelly \& Deacon, 1991). Men are likely to prioritise salary and status while women see career success more as a process of personal development through interesting and challenging work. Such difference may well influence the nature of career benefits from the MBA. This article addresses the current research gap on the nature of career benefits from the MBA and explores how these vary by gender. Implications of these findings for management education are discussed. 


\section{Theoretical Background}

The extent to which qualifications contribute to career success has been part of the debate surrounding the career progress of women. The need to enhance individual attributes in order to compete on an equal footing with men is central to liberal feminism and to the sex difference approach within women in management literature as discussed by Fagenson (1990). This person centred approach argues that key differences between men and women can explain women=s slower career progress and suggests that if women gained more expertise and adopted more male patterns of career planning their career progress would be enhanced. As Burke and McKeen (1994) suggest, many women, in tacit acceptance of this approach, embark on higher level qualifications such as an MBA in order to overcome some of the barriers they face in their careers and as a preparation for senior management. Still (1992) for example has referred to the need for women to be more assertive and to gain the right qualifications and skills and Ong (1993), in a similar vein, has pointed to management education as an important vehicle for equipping women with knowledge, skills and confidence in their own abilities. Research by Leeming and Baruch (1998) indicates that the MBA can reduce discrimination by increasing self- confidence and the ability to combat sexist attitudes and Bickerstaffe (1992), implicitly accepting the power of the MBA in this respect, has exhorted women to use the MBA as a way of breaking through the glass ceiling.

According to this perspective, women need the qualification to gain a foothold on the career ladder and to overcome career barriers. While men may be expected to progress relatively easily up the hierarchy with or without the MBA, the qualification may be 
necessary for women to overcome the disadvantage of their gender. This view is supported by Melamed (1996) who argues that education and qualifications are objective merits which serve to enhance women=s credibility which, through negative stereotypes, would otherwise be considered lower than men=s. Because women are judged by more strict criteria, only the high performers with higher levels of skill, qualifications and abilities than men, can succeed. Men=s credibility, on the other hand, is less dependent on these objective factors. The criteria for their success are less rigid and they can rely on other assets such as access to informal networks as a means of progression. On this basis, as Melamed suggests, qualifications (such as the MBA) may be more important for women than for men and have a greater impact on their careers.

Other writers argue that organisational structures and barriers hidden within the organisation, particularly within the informal context, outweigh any individual differences in attributes so that the power of the MBA to effect career progress and overcome career barriers can be neutralised by structural factors. Cassell and Walsh (1993), for example, have suggested that the person centred approach places responsibility for women $=$ s slow progress up the hierarchy, perhaps unfairly, on women themselves and neglects the role that cultures and structures can play in this process. This conforms with the organisation-structure approach within women in management literature (Fagenson, 1990). Early work within this perspective is associated with Kanter (1977) and Marshall (1984) who both argue that it is organisational structures, such as sector and gender mix, rather than women $=\mathrm{s}$ individual characteristics which determine career progress. More recently, Cockburn (1991) and Witz (1993) argue that male power in organisations is $>$ systemic $=$ in the form of a corporate patriarchy 
whereby men actively create a cultural environment in which women do not flourish. Davidson and Cooper (1992) refer to a Aculture trap@ in which male values in the organisation translate into low self esteem for women while other work discusses the role of the Aold boy $=$ s network@. Such $>$ informal $=$ or hidden barriers cut women off from significant aspects of organisational life such as sources of guidance and information, the means of evaluating colleagues and of establishing relationships, all of which deprive women of important feedback on work related issues (Marshall, 1992; Ibarra, 1993).

Cockburn (1991) and Acker $(1990,1992)$ also address the complexities of organisational cultures and explore the implications of gendering processes for discourses of sexuality and embodiment. Acker challenges the gender neutral assumption of bureaucracies and uses the concept of Aembodimente to analyse women $=\mathrm{s}$ experience in the organisation, in which women managers are seen to embody the emotional, illogical and sexualised aspects of organisations in contrast to male managers who embody gender neutral rationality and decision making (Acker, 1990). This is then translated into interactions and discourse which help to make up gender inside the organisation so that daily practices within the organisation collude with wider cultural messages concerning the inferiority of women. In terms of women and the MBA, these hidden barriers - originating in organisational cultures and practices particularly in the informal context- would be seen as sufficiently strong to override individual characteristics such as qualifications and skill. On this basis, the MBA may be unable to overcome career barriers and be a less than effective tool in securing career success for women. 
These competing perspectives on the power of individual attributes such as qualification levels to facilitate career progress and overcome career barriers - namely the sex difference and the organisation structure approach - form the theoretical framework for the following discussion of women, men and the MBA.

\section{Research Aims}

Against this background, this article presents the findings of a research project conducted in the UK on the impact of the MBA on career progress and the extent to which these benefits might vary by gender. In so doing it hopes to raise issues concerning the role of management education in career development as well as add to the debate on the role of individual attributes such as qualification levels versus the role of structures in determining the career progress of men and women. The article addresses three main questions:

$\mathrm{X}$ How do personal and career benefits from the MBA vary between men and women?

$\mathrm{X}$ Can an individual attribute such as the MBA qualification help women overcome career barriers?

$\mathrm{X}$ How can management education respond to the career development needs of men and women? 


\section{Research Method}

Quantitative methods, comprising stage one of the project, were used to establish the profile of MBA graduates, career progress since graduation from the course and experience of career barriers. Forty business schools in the UK were contacted in 1995 to request access to MBA alumni. Business schools were chosen on the basis of having an established part -time MBA programme. A total of 553 questionnaires were sent to the eleven business schools which had agreed to take part in the survey and these were then distributed by the schools to their MBA alumni. The response rate was $39.9 \%$ with 120 men and 91 women returning their questionnaires. To avoid overloading the goodwill of the business schools concerned (who had forwarded questionnaires to their alumni) it was not possible to send out a letter of reminder to those who had not responded after a certain interval. This may well have reduced the response rate.

The questionnaire covered three main areas. The first section, About You, aimed to gather information on the profile of the MBA graduate in terms of age, qualifications, marital status, children and the impact of children on careers. The second section, Your Employment and the MBA, sought information concerning the labour market position of MBA graduates both before and after the qualification. The final section Your MBA and Career Benefits required information on perceptions of career benefits, experience of career barriers and the effectiveness of the MBA in overcoming those barriers. 
While women were fairly evenly distributed by sector, three quarters of men were to be found in the private and one quarter in the public sectors. All respondents had studied for their qualification part time and had been in the labour market for at least two years at the time of the survey. Part time students were selected on the grounds that their continuity of employment (they were likely to be in work before, during and after the MBA) would facilitate an analysis of career progress whereas full time students were likely to be out of work for at least the duration of the course. Part time and full time students also differ in terms of age and seniority (full time students tend to be younger and less senior) so that the isolation of one group would create a more consistent sample. The two year time lag was stipulated as a minimum to allow time for the MBA to $>$ take effect $=$ and have some impact on career progress.

Qualitative methods were used in stage two of the survey in order to explore in greater depth the nature of personal and career benefits from the MBA and the experience of career barriers. This was carried out in 1996 over a nine month period in the form of semi structured interviews. All respondents from the original sample had been invited to supply contact numbers if they were willing to be interviewed. Just over a half of respondents offered themselves in this way and of those 16 women and 8 men were selected on the grounds of geographical accessibility so that all respondents were located in the South East of England. As nearly two thirds of MBAs in the UK come from this area (AMBA, 1995), this concentration of the interview sample was not thought to be too unrepresentative. Interviews were tape recorded and analysed using Framework Analysis, a grounded theory approach, as outlined by Ritchie and Spenser 
(1996).

\section{Research Results}

\section{Survey Data and Career Benefits}

Survey data assessed changes in careers subsequent to the MBA by examining management role, management function and salary levels before and after the course as well as career progress and career prospects while interview data explored how individuals perceived the role of the MBA in career success. Survey data suggested that both men and women benefited from their qualification in terms of subsequent career progress but that in certain key measures men benefited more than women. These key measures related mainly to changes in management function, management role and pay.

In terms of function, both men and women moved out of junior and into senior positions after the course (with men tending to move out of specialist functions such as IT and production and women tending to move out of support functions such as administration and personnel) but the change for women into senior positions was not so great ( a $4 \%$ change for women and a $16 \%$ change for men). This was despite the fact that women started from a more senior base than men: $20 \%$ of women were in General Management (generally associated with more senior positions) before the MBA 
compared with only $14.7 \%$ of men.

A similar outcome emerged in terms of management role. While the change into senior management was broadly the same for men and women after the MBA (again with higher proportions of women occupying senior roles before the course), when the top four senior roles were taken together - Chair/Chief Executive, Director/Partner, Non Executive Director and Senior Manager - men had the advantage so that the change into these top roles was greater for men than for women (40\% of women occupied senior roles after the MBA compared with $47 \%$ of men). With the top three roles (excluding the category senior manager) the difference was even greater: only $10.1 \%$ of women occupied these roles after the MBA compared with $19.7 \%$ of men $(\mathrm{P}<0.01)$. This indicates that women may be able to break into some, perhaps lower, levels of senior management but experience difficulty progressing further.

Some difference emerged in terms of promotions. Men were more likely to have achieved two or more promotions since the qualification $30 \%$ of men and $24 \%$ of women). However, it was women=s career paths that were more dynamic: $40 \%$ of men and only $32 \%$ of women were promoted within their existing organization while $26 \%$ of women and only $16 \%$ of men changed organization in order to progress $(\mathrm{P}<0.1)$.

\section{Take in table 1}

In terms of pay, as Table 1 illustrates, a small gender difference exists in pay at the lowest pay scale with between $63.6 \%$ and $64.4 \%$ of men and women in this pay bracket 
before the MBA and between $20.2 \%$ and $28.6 \%$ after the MBA. This gap widens at higher pay $(6.2 \%$ of men and only $1.1 \%$ of women earned over , 40,000 before the course) and post MBA (22.5\% of men and only $7.7 \%$ of women earned over , 40,000 after the course). In other words there is a greater similarity between men and women in terms of pay before the MBA (particularly at lower pay scales) but the acquisition of an MBA, rather than closing a pay gap, is associated with a significant gender difference in this respect.

Results from the survey data therefore suggest that the MBA helps both men and women in terms of career progress but that the impact for men may be greater than for women. Men benefit more from their qualification in terms of management function, management role and pay, and with pay the gender gap widens after the qualification. However, while the MBA does not increase women=s earning power at the same rate as it does for men, nor their move into senior management functions or roles, the qualification does enhance their career success. They are more likely to move out of an administrative or support function with their MBA and to move into general management and/or a senior role - though career moves are likely to be associated with a change in organization rather than through an internal labour market.

The sex difference approach within liberal feminism would emphasise certain $>$ deficiencies $=$, such as lack of education or key skills, as contributory factors behind women $=\mathrm{s}$ slower career progress. Enhancing such attributes through, for example, further qualifications and training, would help to create a more level playing field and lead ultimately to career success. To test the relevance of this approach, individual 
profiles and attributes of male and female MBAs were compared to ascertain the extent to which key differences occurred.

Only two areas of significant difference emerged: academic background and family circumstances. In each case, the potential impact on the careers of men and women were explored. In terms of the former, there was no significant difference in terms of qualification levels but a significant difference did emerge with respect to academic background: women tended to have a first degree in Arts/Humanities and men a degree in Science or Engineering. However, no significant difference emerged between men and women of different academic backgrounds in terms of seniority of position either before of after the MBA. In fact, interview data suggests that men and women were equally likely to see their first degree as a source of disadvantage in management: both men and women discussed the need to compensate for what they saw as an inappropriate academic background and claimed that they embarked on the MBA accordingly (men saw a technical background as too narrow and lacking a $>$ people $=$ focus; women saw an Arts or Humanities background as insufficiently rigorous and lacking numerical analysis). On this basis, differences in academic background had little effect on differential career success.

In terms of family circumstances, while women were more likely to be single and without children than men, those women with children were much more likely to believe that their family circumstances had damaged their careers. Such damage was not, however, borne out by the data: women with and without children were broadly comparable in terms of management level before and after the MBA, in term of 
promotions and in terms of career prospects. On this basis, family circumstances appear to have little effect on women $=\mathrm{s}$ ability to climb the corporate ladder.

Therefore, taking academic background and family circumstances together, and given that these were the only significant differences between male and female MBAs in terms of individual attributes and profiles, results from this survey suggest a weakness of the sex difference approach to explain the differential career progress of male and female MBA graduates.

\section{Interview Data and Career Benefits}

Interview data explored how individuals perceived the role of the MBA in career success. Interviews allowed men and women to review their experiences of the course and to assess in detail the benefits they thought the MBA had brought to their working lives. Whereas the survey data indicates certain limitations in the power of the qualification to further the careers of women in relation to those of men, interview data demonstrated consistently women=s enthusiasm for the course. In fact women were generally more positive than men about the impact of the MBA on their careers and on their working lives and they were more specific about the benefits they had received as a result. While they acknowledged the costs of doing the course in terms of workloads and time, they saw the course as rewarding and worthwhile. AI loved it $€$, AI enjoyed it more than other education I=ve done @, AIt was so rewarding @, AI thought it was wonderful@ AIt was brilliant@ Ait (the MBA) gives you a joy for your work@ were

quotes taken from women=s interviews. Men considered the benefits they felt they had 
acquired from the course but they were more measured and cautious in their approach and the benefits they discussed were more concrete in nature. For example, men referred to an increase in their marketability and mobility as a result of having the qualification and to increased knowledge and skill. While women also acknowledged the benefit of the latter, they went on to discuss more abstract advantages of enhanced confidence and credibility, of being able to use the discourse of management with confidence and ease and of the broadening of their networks. An important benefit identified by women concerned the demystification of management discourse through a better understanding of the $>$ jargon $=$ or concepts used. As one woman commented:

$$
\begin{aligned}
& A I=v e \text { noticed that some men, they talk a lot but they don=t necessarily know a } \\
& \text { lot..I didn=t realise } I=d \text { get that from the MBA@ (Wendy) }
\end{aligned}
$$

Enhanced confidence as well as greater understanding of management issues, meant women were able to deal effectively with the pressures and demands of formal meetings. The enhancement of credibility that the MBA conferred was particularly important at meetings where women felt they had achieved a hard won acceptance from male colleagues and where their credibility as experts was generally recognised and valued. All women felt the MBA had equipped them with the necessary skills and confidence to contribute effectively at meetings and, as long as they were well prepared, they felt at ease within this context. The following was a typical comment:

ABeing able to sit in at a very... high powered meeting and say Awhy C... and that to me is the most...to sit down and really argue with the tough 
boys... (Maura)

The interview data, therefore, suggests that women experienced a wider range and in some ways greater levels of benefit from the MBA course than men. As one woman put it, Ait (the MBA) opened my eyes@. Women referred to the ways in which the MBA had helped them overcome certain disadvantages and address vulnerabilities that could well be related to their gender. How the MBA had broadened their networks, helped them overcome lack of credibility, lack of confidence or a tendency to be confused or overawed by the language of $>$ experts $=$ were openly discussed. This impacted on their performance in meetings where they felt valued and in control. None of these factors was considered by men (the >eye opening= experience was missing), though they acknowledged the more traditional benefits of enhanced marketability and knowledge from the course.

While some of these differences may reflect diverse motivations (along gender lines) for taking the MBA, little difference emerged in this respect. The primary motivations for both men and women were intellectual stimulation (24\% and $22 \%$ respectively) followed by the desire for a business qualification ( $15 \%$ and $14 \%$ respectively). The latter was frequently raised by both male and female interviewees as they discussed the need to acquire specific business skills and their subsequent decision to embark on an MBA.

Therefore, men and women appear to benefit differently from the MBA. Women stressed enhanced credibility and confidence from the qualification and how this led to 
a more pro-active approach to work problems and to an ability to engage more fully in work related discussions. This then impacted favourably on how they conducted and managed their working relationships and on their overall job satisfaction. Therefore, while men stressed the more instrumental factors as career benefits, and while they have the advantage in terms of salary and status, it was the factors relating to personal development and job satisfaction that was emphasised by women.

\section{Career Barriers}

To explore the role of structural factors in explaining career progress, respondents were asked to identify, from a list of eleven possibilities, which barriers they had experienced in their careers. The results are summarised in Table 2.

Take in table 2

The weakness of the sex difference approach in explaining the differential career progress of male and female MBA graduates was reflected in women=s choice of career barrier. Women tended to choose attitudinal rather than $>$ individual= factors (the reverse was the case for men). Accordingly, women gave preference to the Men=s Club (56.1\%) Sexual Discrimination (20.9\%) and Prejudice of Colleagues (39.6\%). These were chosen over more >individual $=$ or personal factors such as Lack of Career Guidance, Lack of Training, Insufficient Education or Family and Child care Commitments. For men, however, it was these latter factors that were popular choices over those barriers associated with attitudes or culture. Women also exhibited a higher level of consistency and consensus in their response than men as evidenced by the 
concentration of scores. For example, the top two scores for women were the Men=s Club network (56.1\%) followed by Prejudice of Colleagues (39.6\%) whereas for men the top scores were Lack of Confidence (26.9\%) and Lack of Training/Lack of Career Guidance both of which attracted $25.4 \%$.

Of the range of informal barriers available for choice, the Men $=\mathrm{s}$ Club emerged as a barrier experienced for over a half of women. In fact, when respondents were asked to choose just one option as the largest single barrier, the Men=s Club (chosen by $26.4 \%$ of women) was given preference over Sexual Discrimination (only $1.1 \%$ of women chose this option) or Prejudice of Colleagues (chosen by 12.1\%) even though they were both popular choices as a barrier experienced. In other words, in the more exacting choice of single largest barrier, many women who had previously included the Men=s Club, Sexual Discrimination and Prejudice of Colleagues in their list, now only identified the Men=s Club. This may be because Sexual Discrimination and Prejudice of Colleagues do not describe so powerfully those cultural practices and processes that operate at the informal level to disadvantage women and which Cockburn (1991) has referred to as part of $>$ corporate patriarchy=, even though the end result in terms of curtailed opportunities and structural disadvantage could well be the same.

One interesting source of comparison concerns female MBA graduates and women managers generally in terms of barriers experienced. Such a comparison may indicate the extent to which the MBA has helped to reduce career barriers. On this basis, one might expect MBA graduates, armed with their qualification, to experience fewer career 
barriers than women managers generally. Accordingly, data on career barriers and MBAs outlined above was compared with an Institute of Management (IM) survey of women managers conducted by Coe in 1992. Table 3 sets out the results of this comparison:

\section{Take in table 3}

Rather than exhibiting fewer career barriers than women managers, a higher proportion of women MBAs complained of career barriers than women managers generally. For example, compared with Coe $=\mathrm{s}(1992) \mathrm{IM}$ survey of women managers, the Men $=\mathrm{s}$ Club network was identified by more women MBAs as a barrier in their careers. Fifty six percent of MBAs claimed to have experienced the Men=s Club as a barrier compared to $43 \%$ of women IM managers. A similar but smaller difference occurred for Prejudice of Colleagues. The largest differences between the two samples occurred with the option Lack of Confidence which was chosen by $36 \%$ of MBAs but only $18 \%$ of women managers and the Men=s Club which was chosen by $56 \%$ of MBAs but only $43 \%$ of IM managers. In fact in every single case, a higher proportion of MBAs identified barriers than women IM managers. Finally, whereas $19 \%$ of women managers in Coe $=$ s survey thought they had encountered no barriers, the figure for MBAs was only $8 \%$.

On this basis, the MBA would not appear to be effective in overcoming career barriers. However, differences between the two samples may explain some of the variation. The sample of women managers were all drawn from members of the Institute of Management who tend to be more senior than women managers as a whole (Coe, 1992). Their career success and seniority may reduce the likelihood of career barriers 
being identified and increase the likelihood of no barriers being claimed. While this may explain some of the disparity, little difference emerged in the MBA sample between different management levels: women at senior levels were just as likely as junior women to identify barriers such as the Men=s Club (approximately $52 \%$ in both cases) and equally unlikely as junior women to claim no barriers in their careers (both within the 5-7\% range). At the same time, even when (albeit approximately ) matched for seniority, senior women MBAs (including the roles Senior Managers, Non Executive Directors, Director/Partners and Chairs/Chief Executives only) were still more likely to identify career barriers than women IM managers. In other words, women MBAs are more likely to than women managers generally to experience career barriers and large differences occur between the two samples over Lack of Confidence and the Men=s Club.

This suggests that differences in the effects of the MBA on career success will be mediated by institutional and structural factors. The MBA may therefore be seen as deficient in its ability to help women overcome barriers associated with the so-called >glass ceiling=. In fact, not only has the MBA done little to help women overcome career barriers but perceptions of barriers may be greater among the MBA population than women managers generally.

\section{DISCUSSION}

Question 1: How do personal and career benefits from the MBA vary between men and women? 
Results from this study indicate that men and women MBA benefit from their qualification in different ways. To highlight this difference, a distinction was drawn between $>$ extrinsic $=$ and $>$ intrinsic $=$ career benefits. Extrinsic benefits refer to external career factors such as salary and job status in which, from the survey, men have the advantage and which, according to Nicholson and West (1988), are prioritised by men. Intrinsic factors relate to working relationships and job satisfaction, both of which tend to be prioritised by women (Nicholson and West, 1988). On this basis, men tend to benefit more in terms of $>$ extrinsic $=$ factors of pay and management status. However, women do progress in this respect - for example the MBA may enable them to change out of administrative or support functions into more senior roles. It could well be that the MBA facilitates women=s initial entry into the organisation in a more central role (many of the women interviewed attested to the power of the MBA in this respect) but that once inside they encounter barriers. The relative lack of women in the top four senior roles (despite being on a par with men in terms of proportions in senior management) might suggest a >glass ceiling= at lower levels of the senior management category. As the data suggests, men and women progress in different ways. Men may benefit from an internal labour market which could take them through to the upper levels of senior management, while women $=\mathrm{s}$ experience of $>$ resistance $=$ could explain their more dynamic career path and the need to changing organisations in order to progress.

While women may be disadvantaged in terms of $>$ extrinsic $=$ career benefits, they gain more $>$ intrinsic $=$ benefits from the MBA in the form of enhanced credibility and 
confidence which then gives them more acceptability and personal status within the formal organisation. For men the credential value of the MBA in enhanced mobility and marketability is important whereas for women the experience of the course and the changes it brings in terms of how they see themselves and others appears to be the crucial factor. Women enjoy a process of self discovery, an >eye opening= experience that brings a new awareness of themselves and of the processes and practices that are occurring around them. A similar finding emerged from Hilgert=s (1998) study of six women graduates from an executive MBA programme where the MBA experience was associated with a Anew understanding of the world@ and a Alife changing@ outcome. While the small sample size of male MBA interviewees suggests the need for caution in interpreting the results, the findings do indicate no such change for men.

This difference in perception of benefits may vary for several reasons. If women $=\mathrm{s}$ earlier experiences with respect to education were less rewarding, then they may judge the MBA more favourably than male colleagues. If this were the case, it may go some way to explain their enthusiasm and their more positive attitude towards the course and benefits received. In addition, given that women tend to earn less than men with equivalent qualifications, women may be responding to the disappointing impact on salary by focusing on intrinsic benefits as a way of retrospectively justifying and rationalising their investment in the MBA. Perceptions of career benefits may also reflect differences in male and female styles of speaking, which Tannen (1991) argues can result in men exhibiting a greater reluctance to reveal their feelings. The tendency for men in this study to confine their discussion to instrumental career benefits, and to avoid the self disclosure involved in discussions of intrinsic benefits, may be 
symptomatic of their reticence in this respect.

Equally, perceptions of benefits may vary with existing levels of credibility and personal status. The lesser importance given by men to intrinsic benefits may reflect the advantages of credibility and personal status already conferred on them by their gender. As Melamed (1996) points out, qualification levels are objective merits which are likely to enhance credibility and credentials and which may be more beneficial to women (who are already disadvantaged in these respects) than to men who have less difficulty assuming a managerial role. For example, none of the men interviewed had experienced difficulties acquiring a $>$ voice $=$ at meetings, a problem many women encountered prior to their course, so the MBA had no demonstrable effect for men in this respect.

\section{Research question 2: Can an individual attribute such as an MBA qualification help women overcome career barriers?}

Despite these $>$ intrinsic $=$ advantages for women, the MBA appears to have a limited impact on the glass ceiling. While women may, in implicit acceptance of liberal feminism and the sex difference approach, embark on the programme to enhance individual attributes and so overcome career barriers, structural and attitudinal factors were found to be continuing problems for women. Individual differences between the profiles of male and female MBA graduates in the form of family circumstances and academic background were not found to be sufficiently powerful to explain the relative disadvantage of women in terms of management status and pay. Instead, hidden and 
>informal= barriers, as evidenced by the high proportion of women who identified the Men $=\mathrm{s}$ Club barrier as well as by the prevalence of exclusionary tactics that emerged from interview data, were found to be a strong contributory factor to the relative disadvantage experienced by women despite their having an MBA qualification. This is supported by the interview data in which many women described how a patriarchal organisational culture, operating within the informal organisation, disabled and marginalised them in their everyday work environment.

The informal context has been found to be an important vehicle for career progress (eg Kanter, 1977; Marshall, 1984; Ibarra, 1993). It is within this context that information is exchanged, that important feedback on work issues can be gained and informal alliances forged. With the flattening of organisations, promotions and important projects may be increasingly allocated within this context rather than through formal channels (Simpson, 1998). Exclusion from this informal context can therefore lead to significant career sanctions and may go some way to explain women=s slower career progress. In this sense, informal barriers can be said to $>$ leak= into the formal context and create what could be termed an >informal externality effect=: the source of disadvantage is located within the informal context - exclusion from pub lunches, golf, after work drinks, corridor chats - but, through the processes described above, the effects spill over into the formal organisation.

The MBA, therefore, appears to have done little to help women overcome career barriers located within the informal context. In fact, data suggests that perception of career barriers is greater for women MBAs than for women managers generally. This 
greater perception may relate to the MBA itself - as Leeming and Baruch (1998) indicate in their study, the qualification may sharpen awareness of discriminatory actions and attitudes. If women bring new ways of thinking, new skills and competencies including those relevant to interpersonal behaviour back to the workplace and encounter the same level of disadvantage as before, their frustration may be evidenced by a greater willingness to identify barriers.

In fact, the formal organisation, possibly underpinned by a commitment to equal opportunities, may afford women some protection against overt sexist or discriminatory behaviour. Armed with their MBA, women encountered few if any difficulties in the formal context where they felt their credibility as experts in their field was accepted and valued by male colleagues. Embedded with values of instrumentality, individualism and logic, the MBA may confer on women the $>$ male= characteristics of logical thinking and rationality and reduce women $=\mathrm{s}$ association with the emotional and the illogical. This may go some way to explain the relative ease with which women coped with the pressures and demands of formal meetings even though they were nearly always in the minority in that context. The MBA, in effect, gives them the $>$ stamp of approval= from men within the formal context. It may also explain the low proportion of women who chose Sexual Discrimination as the single largest barrier and the high proportion who chose the Men=s Club. Sexual Discrimination may be seen by women as part of the formal structure and may be associated with formal discriminatory practices that relate to promotion or recruitment decisions. While some women interviewed experienced such discrimination, it was the informal organisation, where the hidden barriers associated with a male culture are located, that was particularly problematic. 


\section{Question 3: How can management education respond to the career development needs of men and women?}

These findings raises several issues for management education as we move into the next millennium. While the MBA may fail women in their attempt to overcome career barriers, and while the small sample size of male interviewees points to the need for further research, the MBA may also be failing men if it does not challenge their attitudes and perceptions. As Johnson et al (1988) suggest, one important expected outcome of an MBA programme is the Abroadening@ of the individual and Alife changing@ development. These developments may well be eluding men - with possible implications for women if men are emerging from their MBA with a lack of awareness of gendered cultures around them. The MBA needs to equip men with an understanding of the diversity they will increasingly confront in the workplace and enable them to learn the values and behaviours appropriate to that diversity. Therefore, while much of the focus for cultural change has been directed at the level of the organisation there is increasing recognition that providers of management education and training play a significant part in influencing management attitudes and practices (Simpson, 1995). For this reason, as Mavin and Bryars (1999) point out, gender should be central to management education and development.

Such education has hitherto had a strong masculine ethos (Sinclair, 1995). Few management textbooks have mainstreamed the issue of gender (Smith, 1997) and the 
politics of gender in mixed group settings frequently disables women who tend to employ less assertive behaviour patterns and consequently may be seen as less powerful. This in turn influences levels confidence and contributions to class or group discussions, further reinforcing a sense of invisibility (Collinson and Hearn, 1996; Linstead, 1995). In addition, sexist attitudes among male lecturers, lack of female role models or a critical mass of women to support each other, together with gender exclusive language and use of examples or case studies may further serve to marginalise women and, according to Smith (1997), create a Achilly@ learning environment. As Mavin and Bryars point out, the idea that a business or management development course is gender neutral simply hides the hierarchy of power in a management development and educational setting. Therefore, courses must integrate gender so as to make gender in management visible from the outset.

According to Marks et al (1997), this requires an overhaul of university management education whose culture remains a serious barrier deterring women learners from maximising their potential: courses and programmes should be scrutinised in terms of delivery and content to determine whether they are meeting the needs of women as well as the needs of men. If, as this research suggests, male attitudes remain a serious barrier to women $=\mathrm{s}$ career progress and if men emerge from their MBA experience with those attitudes largely in tact, then management education is failing both men and women alike albeit in different ways. This implies not simply the inclusion of a managing diversity module into the programme (taking care of that troublesome gender issue!) but a fundamental change in programme development, curriculum revision and teaching methodologies so that perceptions of managers, management and organizations are 
integrated into the whole programme and effectively challenged. Educators need to consider a multiplicity of course objectives as well as multiple methodologies for achieving these objectives. Therefore, while the MBA programme must ensure that it equips women with skills and with confidence in their own abilities to launch them on their own fast track to success, it must also encourage changing attitudes and an eye opening $>$ voyage of discovery $=$ or life changing experience for men.

\section{REFERENCES}

Acker, J. (1990), AHierarchies, Jobs, Bodies: A Theory of Gendered Organisations@, Gender and Society, Vol. 4 No. 2, pp.139-58.

Acker, J. (1992), AGendering Organisational Theory@ in A.J. Mills and P. Tancred (Eds) Gendering Organisational Analysis, London: Sage.

Association of MBAs.(1994), Annual Report, AMBA.

Association of MBAs.(1995), Annual Report, AMBA.

Association of MBAs. (1997), Annual Report, AMBA.

Association of MBAs. (1996), MBA Career Guide $=$ s Annual Survey, London, AMBA

Bartram, D. (1992), AThe Personality of UK Managers: 16PF Norms for Shortlisted Applicants@, Journal of Occupational and Organizational Psychology, Vol.65:pp $159-172$.

Beutell, N. \& Brenner, O. (1986), ASex Differences in Work Values@, Journal of 
Vocational Behaviour, Vol 28, pp29-41

Bickerstaffe, G. (1992), Which MBA? A Critical Guide to the World=s Best

Programmes, 4th edition, London: The Economist Intelligence Unit

Bishop, R. and Soloman, E. (1989), ASex Differences in Career Development: Locus of Control and Career Commitment Effects@, Psychological Reports, Vol 35: pp107-114

Boyatzis, R. \& Renio, A. (1989), A The Impact of an MBA programme on Managerial Abilities@, Journal of Management Development, Vol. 18 No5:pp 25-39

Burke, R. and McKeen, C. (1994), ACareer Development among Managerial and Professional Women@, in M. Davidson and R. Burke (Eds) Women in Management: Current Research Issues, London: Chapman.

Butler, D. \& Geis, F. (1990), ANon Verbal Affect Responses to Male and Female Leaders: Implications for Leadership Evaluation@, Journal of Personality and Social Psychology, Vol. 58, pp18-59.

Cassell, C. \& Walsh, S. (1993), ABeing Seen but not Heard: Barriers to Women=s Equality in the Workplace@, The Psychologist, Vol 6, pp110-114.

Chapman, T. (1989), AWomen Graduates in Management and the Professions@, Women in Management Review, Vol.4 No2, pp35-42.

Cockburn, C. (1991), In the Way of Women: Men=s Resistance to Sex Equality in

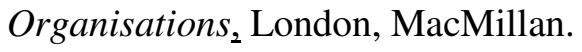

Coe, T. (1992), The Key to the Men=s Club, Corby, Institute of Management.

Coe, T, and Stark, A. (1992), Manager Mobility in the 1990s, Corby, Institute of Management

Collinson, D. \& Hearn, G. (1996), ABreaking the Silence on Men, Masculinities and Managements@ in D. Collinson and G. Hearn (Eds) Men as Managers and Managers 
as Men, London, Sage.

Cox, T. \& Harquil, C. (1991), ACareer Paths and Career Success in Early Career Stages of Male and Female MBAs@, Journal of Vocational Behaviour, Vol 39, pp54-75.

Davidson, M. \& Cooper, C. (1992), Shattering the Glass Ceiling, London, Paul Chapman.

Dix, C. (1990), A Chance for the Top - The Lives of Women Business Graduates, London, Bantam Press.

Dix, C. (1991), Enterprising Women, London, Bantam Press.

Fagenson, E. (1990), AAt the Heart of Women in Management Research: Theoretical and Methodological Approaches and their Biases@, Journal of Business Ethics, Vol.9, pp267-274.

Ferrario, M. (1994), AWomen as Managerial Leaders@, in R. Burke \& M. Davidson (eds) Women in Management: Current Research Issues, London, Paul Chapman

Gitlow, A. (1992), Being the Boss: The Importance of Leadership and Power, Homewood, IL,Irwin.

Goffee, R. \& Nicholson, N. (1994), ACareer Development in Male and Female Managers Convergence or Collapse?@ in M. Davidson and R. Burke (Eds) Women in Management: Current Research Issues, London, Paul Chapman.

Hall, D. (1976), Careers in Organisations, Santa Monica, CA, Goodyear Hilgert, A. (1998), AProfessional Development of Women and the MBA@, Journal of Management Development Vol.17 No. 9, pp629-643

Ibarra, H. (1993) APersonal Networks of Women and Minorities in Management: A Conceptual Framework@, Academy of Management Review, Vol.18 No 1, pp56-87. Itzin, C. (1995) AThe Gender Culture in Organizations@, in C. Itzin and J. Newman 
(Eds) Gender, Culture and Organizational Change, London, Routledge.

Johnson, T. McLaughlin, S. Saari, L. \& Simmerle, D. (1988), The Demand and Supply for University-based Executive Education, Graduate Management Admission Council, Los Angeles, CA

Kanter, R. (1977), Men and Women in the Corporation, New York, Basic. Kretovics, M. (1999), AAssessing the MBA What do our students learn?@ The Journal of Management Development, Vol.18 No.2, pp125-136

Leeming, A. and Baruch, Y. (1998), AThe MBA as a Bridge over the Troubled Waters of Discrimination@, Women in Management Review, Vol. 13 No 3, pp95 - 104

Linstead, S. (1995), A Averting the Gaze: gender and power on the perfumed picket line@, Gender, Work and Organization, Vol. 2. No 4, pp192-206

Lloyd, B. (1987) Women MBA's: Problems and Prospects, London:Business Graduates Association

Maddock, S. \& Parkin, D. (1994), AGender Cultures and How they Affect Women at Work@ in M. Davidson and R. Burke (Eds) Women in Management: Current Research Issues, London, Chapman.

Mallon, M. \& Cassell, C. (1999), AWhat do Women Want? The perceived develoment needs of women managers@ The Journal of Management Development, Vol. 18. № 2, pp137-151

Marks, R., Dugan, M. \& Payn, B. (1997), Why Women drop out of graduate management education: answers from GMAC data selections, Graduate Management Admissions Council, Autumn, pp 6-17

Marshall, J. (1984), Women Managers: Travellers in a Male World, Chichester: Wiley Marshall, J. (1992), AOrganisational Cultures: Attempting Change often Means More of 
the Same@, The Journal: Women in Organisations and Management, Vol. 3 pp4-7. Mavin, S. \& Bryars, P. (1999), AGender on the Agenda of Management Education@, Women in Management Review, Vol.14 No. 3, pp 99-104

Melamed, T. (1996), ACareer Success: An Assessment of a Gender Specific Model@, Journal of Occupational and Organisational Psychology, Vol.69 No.3, pp217-242.

Newman, J. \& Williams, F. (1995), ADiversity and Change: Gender, Welfare and Organizational Relations@, in C. Itzin and J. Newman (Eds) Gender, Culture and Organizational Change, London, Routledge.

Nicholson, N. \& West, M. (1988), Managerial Job Change: Men and Women in Transition, Cambridge University Press.

O=Leary, V. \& Ickovics. J. (1990), ACracking the Glass Ceiling: Overcoming stereotypes and isolation@ in U. Sekaran and F. Leong (Eds) Pathways to Excellence: New Patterns for Human Resource Utilization, Beverly Hills, CA, Sage

Olson, J. \& Frieze, I. (1987), AIncome Determinants for Women in Business@ in A. Stromberg, L. Larwood and B. Gutek (Eds) Women and Work, Newbury Park, CA, Sage

Olson, J. \& Good, D. (1990), A The Effects of Job Type and Industry on the Income of male and female MBAs@, Journal of Human Resources, Vol.22, pp 532-540

Ong, B. (1993), Follow up Study of Female MBA/MA/MSc Students, Keele, Centre for Health Planning and Management, June.

Parkin, D. \& Maddock, S. (1995), A A Gender Typology of Organizational Cultures@ in C. Itzin and J. Newman (Eds) Gender, Culture and Organizational Change, London, Routledge.

Ritchie, J. \& Spencer, L. (1996), AQualitative Data Analysis for Applied Policy 
Research@ in A. Bryman and R. Burgess (Eds), Analyzing Qualitative Data, London, Routledge.

Roman, M. (1990), AWomen Beware: An MBA Doesn=t Mean Equal Pay@, Business Week 29 October, 47.

Russo, N., Kelly, M. \& Deacon, M. (1991), AGender and sex related attribution: beyond individualistic conceptions of achievement@ Sex Roles, Vol. 25, pp331-350

Rycroft, T. (1989), Survey of Women Managers, Corby, Institute of Management.

Schein, E. (1978), Career Dynamics: Matching individual needs and organizational needs, Reading, MA, Addison Wesley

Schneer, J. \& Reitman, F. (1990), A Effects of Employment Gaps on the careers of MBAs: More Damaging for Men than Women?@ Academy of Management Journal Vol. 33 No 2, pp39-406.

Simpson, R. (1995), A Is Management Education on the Right Track for Women? @ Women in Management Review, Vol.10 No. 6, pp3-8

Simpson, R. (1996), ADoes an MBA Help Women?@, Gender Work and Organisation, Vol. 3 No. 2, pp 13-19

Simpson, R. (1998), APresenteeism, Power and Organisational Change: Long Hours as a Career Barrier and the Impact on the Working Lives of Women Managers@, British Journal of Management, Vol. 9, ppS37 - 50

Sinclair, A. (1995), A Sex and the MBA@, Organization, Vol.2 No 2, pp295-317.

Sinclair, A. \& Hintz, P. (1991), ADeveloping Managers: Re-examining Ten Myths about MBAs and Managers@, Journal of Management Development, Vol.10 No 7, pp53-65

Smith. C. (1997), A Gender Issues on Management Education: A new teaching 
resource @, Women in Management Review, Vol. 12 No 3, pp100-104

Still , L. (1992), A Breaking the Glass Ceiling@, Women in Management Review, Vol 17 No 5, pp3-8.

Strober, M. (1982), AThe MBA: Same passport to Success for Men and Women?@ in P. Wallace (Ed) Women in the Workplace, Boston, Aubern House.

Sturges, J. (1999), AWhat it Means to Succeed: personal Conceptions of Career Success Held by Male and Female Managers at Different Ages@ British Journal of Management,_Vol 10, pp239-252

Subich, L., Barret, G., Doverspike, D. \& Alexander, R. (1989), AThe effects of sex role related factors on occupational choice and salarye, in R. Hartmann and B. O=Farrell (Eds) Pay Equity: Empirical Inquiries, Washington DC, National Academy Press

Tannen, D. (1991), You Just Don=t Understand, London, Virago

Summers, T. (1988), AExamination of Sex Differences in Expectations of Pay and Perceptions of Equity in Pay@, Psychological Reports, Vol 62: pp491-496.

Walby, S. (1988), AGender Politics and Social Theory@, Sociology, Vol. 22 No. 2, pp215-232.

Wallace, P. (1989), MBAs on the Fast Track: The Career Mobility of Young Managers, New York, Ballinger.

Witz, A. (1992), Professions and Patriarchy, London, Routledge. 
Table 1: MBA Graduates and Salary Levels \%

\begin{tabular}{|l|l|l|l|l|}
\hline & \multicolumn{2}{|c|}{ Men } & \multicolumn{2}{c|}{ Women } \\
\hline & Before MBA & After MBA & Before MBA & After MBA \\
\hline Under 25,000 & 63.6 & 20.2 & 64.4 & 28.6 \\
\hline $25-35,000$ & 26.4 & 43.4 & 32.2 & 52.7 \\
\hline $36-40,000$ & 3.9 & 14.0 & 2.2 & 11.0 \\
\hline Over 40,000 & 6.2 & 22.5 & 1.1 & $7.7 *$ \\
\hline N & 129 & 129 & 91 & 91 \\
\hline
\end{tabular}


$* \mathrm{P}<0.01$

Table 2: MBAs and Career Barriers

\begin{tabular}{|c|c|c|}
\hline & \multicolumn{2}{|c|}{ Barrier Experienced \% } \\
\hline & Women & Men \\
\hline Inflexible Working Patterns & 18.7 & 19.3 \\
\hline Lack of Training Provision & 20.1 & 25.4 \\
\hline Insufficient Education & 7.7 & 11.5 \\
\hline Family Commitments & 17.6 & 20.8 \\
\hline Lack of Adequate Childcare & 14.3 & 2.32 \\
\hline Lack of Confidence & 36.3 & 26.9 \\
\hline Lack of Career guidance & 29.7 & 25.4 \\
\hline Prejudice of Colleagues & 39.6 & 21.62 \\
\hline Social Pressures & 13.2 & $3.8 \quad 1$ \\
\hline Men $=$ s Club Network & 56.1 & 8.42 \\
\hline Sexual Discrimination & 20.9 & 0 \\
\hline No Barriers & 7.7 & $24.6 \quad 1$ \\
\hline $\mathrm{N}$ & 91 & 130 \\
\hline
\end{tabular}


Table 3 : Barriers experienced by Female MBA Graduates and Women Managers

\begin{tabular}{|l|l|l|}
\hline & Women Managers & Women MBAs \\
\hline & Barriers \% & Barriers \% \\
\hline Men=s Club Network & 43 & 56 \\
\hline Prejudice of Colleagues & 35 & 40 \\
\hline Lack of Career Guidance & 28 & 30 \\
\hline Sexual Discrimination & 23 & 21 \\
\hline Lack of Training & 18 & 24 \\
\hline Lack of Confidence & 18 & 13 \\
\hline Family Commitments & 12 & 13 \\
\hline Inflexible Work Patterns & 12 & 8 \\
\hline Social Pressures & 7 & 19 \\
\hline Insufficient Education & 19 & \\
\hline No Barriers & & \\
\hline
\end{tabular}

Adapted from Coe, p15 (figures rounded to the nearest whole number for comparison) 